2 Received Date : 09-Oct-2015

3 Revised Date :23-Feb-2016

4 Accepted Date : 11-Apr-2016

5 Article type : Original Article: Airway Diseases

6 Editor: Douglas Robinson

7

8

\title{
Residential greenness is differentially associated with childhood allergic rhinitis and aeroallergen sensitization in seven birth cohorts
}

\section{(C)}

Elaine Fuertes ${ }^{\mathrm{a}}$, Iana Markevych ${ }^{\mathrm{a}, \mathrm{b}}$, Gayan Bowatte ${ }^{\mathrm{c}}$, Olena Gruzieva ${ }^{\mathrm{d}}$, Ulrike Gehring ${ }^{\mathrm{e}}$, Allan Becker ${ }^{\mathrm{f}}$, Dietrich Berdel $^{\mathrm{g}}$, Andrea von Berg ${ }^{\mathrm{g}}$, Anna Bergström ${ }^{\mathrm{d}}$, Michael Brauer ${ }^{\mathrm{h}, \mathrm{i}}$, Bert Brunekreef ${ }^{\mathrm{e}}$, Irene Brüske $^{\mathrm{a}}$, Chris Carlsten ${ }^{\mathrm{h}, \mathrm{i}}$, Moira Chan-Yeung ${ }^{\mathrm{i}}$, Shyamali C Dharmage ${ }^{\mathrm{c}}$, Barbara Hoffmann ${ }^{\mathrm{j}, \mathrm{k}}$, Claudia Klümper $^{\mathrm{j}}$, Gerard H., Koppelman ${ }^{1, \mathrm{~m}}$, Anita Kozyrskyj ${ }^{\mathrm{n}, \mathrm{o}}$, Michal Korek ${ }^{\mathrm{d}}$, Inger Kull ${ }^{\mathrm{d}, \mathrm{p}, \mathrm{q}}$, Caroline Lodge $^{c}$, Adrian Lowe ${ }^{c}$, Elaina MacIntyre ${ }^{\mathrm{r}}$, Göran Pershagen ${ }^{\mathrm{d}}$, Marie Standl ${ }^{\mathrm{a}}$, Dorothea Sugiri ${ }^{\mathrm{j}}$, Alet Wijga $^{\text {s }}$, MACS, Joachim Heinrich ${ }^{\text {a,t }}$
a) Institute of Epidemiology I, Helmholtz Zentrum München - German Research Center for Environmental Health, Neuherberg, Germany

b) Division of Metabolic and Nutritional Medicine, Dr. von Hauner Children's Hospital, LudwigMaximilians-University of Munich, Munich, Germany

c) Allergy and Lung Health Unit, Melbourne School of Population and Global Health, The University of Melbourne, Australia

d) Institute of Environmental Medicine, Karolinska Institutet, Stockholm, Sweden

e) Institute for Risk Assessment Sciences, Utrecht University, Utrecht, The Netherlands

f) Department of Pediatrics and Child Health, University of Manitoba, Winnipeg, Canada

g) Research Institute, Department of Pediatrics, Marien-Hospital Wesel, Germany

h) School of Population and Public Health, University of British Columbia, Vancouver, Canada

This is the author manuscript accepted for publication and has undergone full peer review but has not been through the copyediting, typesetting, pagination and proofreading process, which may lead to differences between this version and the Version of Record. Please cite this article as doi: 10.1111/all.12915

This article is protected by copyright. All rights reserved 
i) Department of Medicine, University of British Columbia, Vancouver, Canada

j) IUF - Leibniz Research Institute for Environmental Medicine, Heinrich-Heine University of Düsseldorf, Germany

\section{Corresponding author:}

Elaine Fuertes, $\mathrm{PhD}$

n) Department of Pediatrics, Faculty of Medicine \& Dentistry, Women and Children's Health Research Institute, Edmonton, Canada

o) School of Public Health, University of Alberta, Edmonton, Canada

p) Department of Clinical Science and Education, Karolinska Institutet, Stockholm, Sweden

q) Sachs' Children and Youth Hospital, Stockholm, Sweden

r) Department of Environmental Health, Public Health Ontario, Toronto, Canada

s) Center for Nutrition, Prevention and Health Services, National Institute of Public Health and the Environment, Bilthoven, The Netherlands

t) Institute and Outpatient Clinic for Occupational, Social and Environmental Medicine, University Hospital Munich, Ludwig-Maximilians-University of Munich, Munich, Germany

Institute of Epidemiology I, Helmholtz Zentrum München - German Research Center for

Environmental Health, Ingolstädter Landstraße 1, 85764 Neuherberg, Germany

Phone: +49 893187 4235; Fax: +49 8931873380

elaine.fuertes@helmholtz-muenchen.de

Short title: Residential greenness and allergic rhinitis

Key Words: allergic rhinitis; birth cohorts; greenness; NDVI; sensitization

Abstract word count: 248

Text word count (introduction to discussion): 3634

This article is protected by copyright. All rights reserved 
The BAMSE study was supported by the Swedish Research Council, the Swedish Heart-Lung Foundation, Stiftelsen Frimurare Barnhuset i Stockholm, Matsumura's donation, the Stockholm County Council, the Swedish Environmental Protection Agency, the Swedish Society for Medical Research, the Swedish Foundation for Strategic Research and the Swedish Research Council for Health Working Life and Welfare. The PIAMA study is supported by The Netherlands Organization for Health Research and Development, The Netherlands Organization for Scientific Research, The Netherlands Asthma Fund, The Netherlands Ministry of Spatial Planning, Housing, and the Environment, and The Netherlands Ministry of Health, Welfare and Sport. The GINIplus study was mainly supported for the first 3 years by the Federal Ministry for Education, Science, Research and Technology (interventional arm) and Helmholtz Zentrum Munich (former GSF) (observational arm). The 4 year, 6 year and 10 year followup examinations of the GINIplus study were covered from the respective budgets of the 5 study centres (Helmholtz Zentrum Munich (former GSF), Marien-Hospital Wesel, LMU Munich, TU Munich and from 6 years onward also from IUF - Leibniz Research-Institute for Environmental Medicine) and a grant from the Federal Ministry for Environment (IUF, FKZ 20462296). The LISAplus study was mainly supported by grants from the Federal Ministry for Education, Science, Research and Technology and in addition from Helmholtz Zentrum Munich (former GSF), Helmholtz Centre for Environmental Research - UFZ, Leipzig, Marien-Hospital Wesel, Pediatric Practice, Bad Honnef for the first 2 years. The 4 year, 6 year and 10 year follow-up examinations of the LISAplus study were covered from the respective budgets of the involved partners (Helmholtz Zentrum Munich (former GSF), Helmholtz Centre for Environmental Research - UFZ, Leipzig, Marien-Hospital Wesel, Pediatric Practice, Bad Honnef, IUF - Leibniz-Research Institute for Environmental Medicine) and in addition by a grant from the Federal Ministry for Environment (IUF, FKZ 20462296). The CAPPS study was supported by the Canadian Institutes of Health Research, the British Columbia Lung Association and the Manitoba Medical Service Foundation. The SAGE study was supported by the Canadian Institutes of Health Research. The first 6 years of the MACS study were funded by Nestec Ltd, a subsidiary of Nestlé Australia. The 12 year follow-up was funded by a project grant from the Asthma Foundation of Victoria. The NHMRC funded Centre for Air Quality and Health Research and evaluation (CAR) funded geocoding of participants' addresses. The "Traffic Asthma and Genetics" collaboration was supported by the AllerGen Networks of Centres of Excellence. The ESCAPE (grant agreement number: 211250) research received funding from the European Community's Seventh Framework Program

This article is protected by copyright. All rights reserved 
90 (FP7/2007-2011). The aforementioned funding sources had no involvement in the study design, in the 91 collection, analysis and interpretation of data, in the writing of the report and in the decision to submit 92 the article for publication.

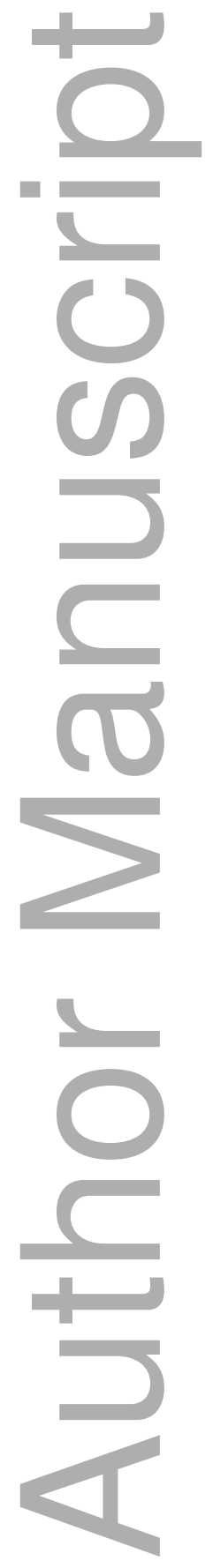

This article is protected by copyright. All rights reserved 


\section{ABSTRACT}

94 Background: The prevalence of allergic rhinitis is high but the role of environmental factors remains

95 unclear. We examined cohort-specific and combined associations of residential greenness with allergic rhinitis and aeroallergen sensitization based on individual data from Swedish (BAMSE), Australian (MACS), Dutch (PIAMA), Canadian (CAPPS and SAGE) and German (GINIplus and LISAplus) birth cohorts $(\mathrm{N}=13,016)$.

Methods: Allergic rhinitis (doctor diagnosis/symptoms) and aeroallergen sensitization were assessed in children aged 6-8 years in six cohorts and 10-12 years in five cohorts. Residential greenness was defined as the mean Normalized Difference Vegetation Index (NDVI) in a 500m buffer around the home address at the time of health assessment. Cohort-specific associations per 0.2 unit increase in NDVI were assessed using logistic regression models and combined in a random-effects meta-analysis.

104 Results: Greenness in a 500m buffer was positively associated with allergic rhinitis at 6-8 years in 105 BAMSE (odds ratio=1.42, 95\% confidence interval [1.13, 1.79]) and GINI/LISA South (1.69 [1.19, $1062.41])$ but inversely associated in GINI/LISA North $(0.61[0.36,1.01])$ and PIAMA $(0.67[0.47,0.95])$.

107 Effect estimates in CAPPS and SAGE were also conflicting but not significant $(0.63[0.32,1.24]$ and $1081.31[0.81,2.12]$, respectively). All meta-analyses were non-significant. Results were similar for aeroallergen sensitization at 6-8 years and both outcomes at 10-12 years. Stratification by $\mathrm{NO}_{2}$ concentrations, population density, an urban versus rural marker and moving did not reveal consistent

111 trends within subgroups.

112 Conclusion: Although residential greenness appears to be associated with childhood allergic rhinitis 113 and aeroallergen sensitization, the effect direction varies by location.

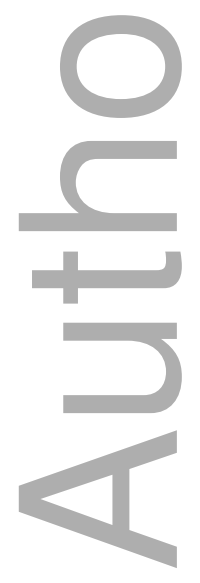

This article is protected by copyright. All rights reserved 


\section{INTRODUCTION}

115 Green environments are thought to impart beneficial effects on health by increasing physical activity

116 and stress relief, and by facilitating social interactions. They are also associated with reduced noise, air

117 pollution and heat exposures (1). However, surrounding greenness may play a more complex role on

118 allergic health outcomes. Although a causal relationship remains to be established, studies suggest that

119 children who spend more time in outdoor green environments during early-life may benefit from

120 exposure to a greater number and diversity of beneficial microbes (2,3). A similar protective effect has

121 also been documented between sensitization and a diverse early-life exposure to indoor allergens and

122 microbes (4). However, among those sensitized, exposure to pollen-releasing plants and outdoor fungi

123 may exacerbate allergic symptoms in later childhood (5).

124

125 The few epidemiological studies that have examined associations between residing in/near green places

126 and allergic health outcomes have yielded inconsistent results. Studies report increased (6), no (7),

127 protective (2,8), or conflicting (9) effects, and a recent study concluded that associations appear to

128 depend on the type of greenness evaluated (for example, parks versus forests (10)). These studies differ

129 with respect to their designs, outcomes, populations and green exposure assessment strategies, which

130 may in part explain some of these discrepant findings. For example, the aforementioned studies defined

131 vegetation level using data on tree canopy cover $(6)$, vegetation or land-use types $(2,8)$, the Normalized

132 Difference Vegetation Index (NDVI) (7,9) or several of these measures (10). It is currently unclear

133 which of these exposure metrics may be best. While some more specific measures are able to classify

134 large green areas into land use types (such as the CORINE land use European data), they are not

135 commonly available on a global scale and do not include small green areas. Further, it is possible that

136 different metrics may be more or less relevant to specific pathways. For example, land use data may be

137 very useful for studying physical activity levels, but this is unlikely to represent the main pathway by

138 which greenness might affect allergic diseases.

139

140 As a general measure of vegetation presence, the NDVI index captures vegetation of all sizes using a

141 globally harmonized method, and we chose to use this index to examine cross-sectional associations

142 between residential greenness and allergic rhinitis and aeroallergen sensitization during childhood and

143 early adolescence in seven birth cohorts from Australia, Canada, Germany, the Netherlands and

144 Sweden. As suggestive evidence exists that air pollutants and urbanization may act as confounders or

This article is protected by copyright. All rights reserved 
145 effect modifiers in greenness-health relationships $(11,12)$, we tested interactions between nitrogen

146 dioxide $\left(\mathrm{NO}_{2}\right)$ concentrations, population density and a rural/urban indicator with residential

147 greenness, and also adjusted for these factors.

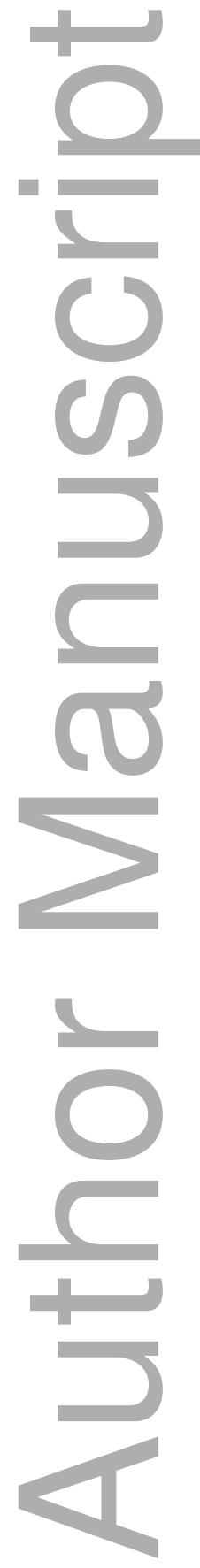

This article is protected by copyright. All rights reserved 
METHODS

Data sources

150 Seven birth cohorts participated: BAMSE (13), CAPPS (14), GINIplus (15), LISAplus (16,17), MACS

151 (18), PIAMA (19) and SAGE (20). Data on several health outcomes, environmental exposures and

152 covariates from all cohorts except MACS had already been harmonized as part of the Traffic, Asthma

153 and Genetics (21) and European Study of Cohorts for Air Pollution Effects (22) collaborations. MACS

154 is here included as this Australian birth cohort adds additional vegetation and geography heterogeneity.

155 Each cohort received ethical approval from their local authorized Institutional Review Boards.

Outcome assessment

158 We focused on health outcomes during childhood (6-8 years) and early adolescence (10-12 years).

159 Information on the cohort-specific study designs and outcome definitions, which varied slightly by

160 cohort, are provided in the Supplemental Information, Table S1. Allergic rhinitis was defined based on

161 a diagnosis during a physician assessment at a follow-up visit in CAPPS and SAGE, parental report of

162 a doctor's diagnosis in GINIplus and LISAplus, parental symptom report in PIAMA and BAMSE and

163 parental symptom or treatment report in MACS.

164

165 Sensitization was assessed by skin prick testing for CAPPS, MACS and SAGE, with a positive reaction

166 defined as having a wheal diameter of $\geq 3 \mathrm{~mm}$. For all other cohorts, sensitization was assessed by

167 measuring allergen specific IgE levels, with a positive reaction defined as any value $\geq 0.35 \mathrm{kU} / \mathrm{L}$, the

168 lower detection limit of the assay. Birch, Dactylis, mugwort, ragweed, rye, timothy grass, trees and

169 weeds were considered as outdoor aeroallergens. Alternaria alternata, cats, Cladosporium herbarum,

170 cockroaches, dogs, feathers, house dust mites and molds were considered as indoor aeroallergens. All

171 available aeroallergens were included in the sensitization analyses. Not all cohorts had information on

172 all aeroallergens or health data at both time points (Supplemental Information, Table S1).

173

174

\section{Greenness assessment}

175 The NDVI, a green biomass density indicator, was used as a surrogate for surrounding greenness. Its 176 calculation is based on the difference of surface reflectance in visible $(0.4-0.7 \mu \mathrm{m})$ and near-infrared

$177(0.7-1.1 \mu \mathrm{m})$ wavelengths. Values range from negative one (water) through zero (rock, sand, snow) to 178 positive one (dense green vegetation) (23). The assignment of NDVI to the home addresses of all

This article is protected by copyright. All rights reserved 
179

180

181

182

183

184

185

186

187

188

189

190

191

192

193

194

195

196

197

198

199

200

201

202

203

204

205

206

207

208

209

cohort participants was done using a harmonized method previously described (24). First, to achieve maximum exposure contrasts, cloud-free satellite images corresponding as close as possible to the spring and summer months during the year of birth of the participants were centrally selected for all cohorts and used to calculate NDVI maps. Negative NDVI pixels were set to zero (replication of analyses with negative NDVI values left as is or set to missing yielded the same results). Second, these images were used to calculate mean greenness in $500 \mathrm{~m}$ and $1000 \mathrm{~m}$ circular buffers around the home addresses of participants at 6-8 and 10-12 years of age in order to assess current greenness exposure effects. The $500 \mathrm{~m}$ buffer was a priori selected as the main buffer as it is a proximal measure of a child's neighborhood, may be less prone to exposure misclassification and has been used in previous studies on children (e.g. $(25,26))$. The $1000 \mathrm{~m}$ buffer captures a larger area around an individual's neighborhood and was used as a sensitivity analysis.

The NDVI values used in all main analyses were derived from satellite maps taken at the time of birth of the participants and assigned to their 6-8 and 10-12 year addresses under the assumption that the spatial distribution of greenness would remain stable between these time points. To test this assumption, a second set of NDVI values was created based on satellite maps selected approximately a decade after the birth of the participants and assigned to these same 6-8 and 10-12 year addresses. All main analyses were replicated with this second set of NDVI values. Details of the months and years used for the NDVI assignments for each cohort are provided in the Supplemental Information, Table S1.

\section{Statistical analysis}

Cohort-specific associations were analyzed using logistic regression. Odds ratios are reported per 0.2 unit increase in NDVI (approximately two times the standard deviation in the total population) with corresponding 95\% confidence intervals. The GINIplus and LISAplus cohorts were pooled as the study designs are nearly identical and associations are presented per geographical area instead (the rural GINI/LISA North area and GINI/LISA South, which covers the urban city of Munich and its surroundings). Random-effects meta-analysis was used to calculate combined estimates to allow for potential within-and between-cohort heterogeneity (27). The $\mathrm{I}^{2}$ statistic was used to examine statistical heterogeneity among cohort-specific effect estimates and can be interpreted as the percentage of the variability in effect sizes attributable to the between-study variability rather than sampling error $(28)$. $\mathrm{I}^{2}$

This article is protected by copyright. All rights reserved 
values between $50-90 \%$ and $75 \%-100 \%$ represent substantial and considerable heterogeneity,

211 respectively (29). Cochran's Q test was used to test for significant heterogeneity. Analyses for CAPPS,

212 GINI/LISA North, GINI/LISA South, PIAMA, SAGE and the combined meta-analyses (using package 213 "meta" (30)) were conducted centrally using the statistical program R, version 3.1.1 (31). Analyses for 214 BAMSE and MACS were done locally using STATA, version 13 and 13.1 (32), respectively, following 215 the same analysis plan.

Minimally adjusted models were adjusted for sex and age. Main models were additionally adjusted for parental atopy (not included for MACS as $97 \%$ of participants had a history of parental atopy), older siblings, maternal smoking during pregnancy, secondhand smoke exposure concomitant with the time of health outcome assessment (not available for MACS), socioeconomic status (defined as the highest education attained by either parent for BASME, GINI/LISA North, GINI/LISA South, MACS and PIAMA, and maternal age at birth for CAPPS and SAGE), group (intervention for CAPPS, GINI/LISA North, GINI/LISA South, PIAMA and MACS), region (CAPPS and PIAMA only) and cohort (GINI/LISA North and GINI/LISA South only). The influence of additional adjustments for birth weight and exposure to furry pets and mold/dampness in the home at the time of health outcome assessment was examined in sensitivity analyses (MACS not included as these data were generally not available). Covariates were defined as similarly as possible across cohorts using questionnaire-derived information and their selection is based on previous combined analyses of these cohorts with regard to allergic rhinitis and sensitization $(9,22,33)$.

\section{Effect modification}

232 To assess effect modification by sex, regression analyses were run including an interaction term 233 between NDVI and sex. In a separate analysis, regression analyses were also run separately for males and females. Effect modification by cohort-specific tertiles of $\mathrm{NO}_{2}$ concentrations and population density in a 1000m buffer around the home address was also assessed, and models were run stratified by whether participants lived in urban or rural surroundings (data sources and methodology described in the Supplemental Information, page 3). Models were also stratified by whether a child had moved between 1) birth and 6-8 years when considering the childhood health outcomes and between 2) birth and 10-12 years when considering the adolescent health outcomes (CAPPS and SAGE not included as data on moving behavior were unavailable).

This article is protected by copyright. All rights reserved 
243 In total, 13016 children had available information on NDVI exposure and at least one outcome of 244 interest at one time point. The included cohorts varied in size from 3339 children in PIAMA to 327

245 children in MACS (Table 1). Of those with available data, 9.8\% (1182/12007) had allergic rhinitis and $24630.3 \%(2246 / 7408)$ were sensitized to at least one aeroallergen at the age of 6-8 years (13.6\%

247 (1346/9885) and 42.1\% (1650/3922) are the respective values for 10-12 years). Allergic rhinitis 248 prevalence was lowest in GINI/LISA North and highest among cohorts recruited on the basis of family 249 history (MACS and CAPPS) and SAGE.

\section{Distribution of NDVI values}

252 The mean and range of NDVI values in a 500m buffer were similar across cohorts (Figure 1). NDVI 253 estimates in a 500m buffer were highly correlated with those in a 1000m buffer (Pearson's $\mathrm{r}>0.88$ ). 254 NDVI estimates in the 500m buffer assessed to the childhood and early adolescence addresses were 255 weak to moderately correlated across cohorts for those who moved between these two time points (range of $r=0.26$ in PIAMA to $r=0.55$ in BAMSE). NDVI estimates derived using satellite maps obtained for the year of birth and approximately 10 years later $(r>0.73)$ were highly correlated. As it was not possible to obtain cloud-free images for the same months for all cohorts and given that months have different meanings in the different cohorts (for example, when contrasting European and Australian seasons), comparing NDVI distributions across cohorts is not appropriate. Cohort locations and the distribution of NDVI values per cohort are depicted in the Supplemental Information, Figure S1.

\section{Associations between health outcomes and NDVI}

The adjusted cohort-specific associations per 0.2 increase in NDVI for the main models are presented in Figures 2 and 3 for outcomes assessed during childhood (6-8 years) and early adolescence (10-12 years), respectively (results per cohort-specific interquartile range increase in NDVI presented in the Supplemental Information, Figure S2). The minimally adjusted models (for age and sex only) were similar (not shown). Greenness in a 500m buffer was positively associated with allergic rhinitis at 6-8 
272 in GINI/LISA North $(0.61[0.36,1.01])$ and PIAMA $(0.67[0.47,0.95])$. The effect estimates in the 273 Canadian cohorts were also conflicting but not significant $(0.63[0.32,1.24]$ and $1.31[0.81,2.12]$ for 274 CAPPS and SAGE, respectively). The pattern of associations within each cohort for aeroallergen 275 sensitization was similar to those with allergic rhinitis. The pattern also did not differ when 276 associations were stratified into categories of indoor and outdoor allergens, with the exception of 277 SAGE for which the direction of effect estimates varied across outcomes. This suggests that the 278 observed associations with aeroallergen sensitization are not attributable to a single allergen.

Similar results were obtained for both health outcomes at 10-12 years for the four cohorts with 281 available data at both time points. Associations in the seventh cohort MACS, for which health data were only available at this latter age, were non-significant for allergic rhinitis $(0.96[0.59,1.57])$ and inverse for aeroallergen sensitization $(0.57[0.34,0.96])$.

Effect estimates were consistent when NDVI was assessed in a $1000 \mathrm{~m}$ buffer and when models were further adjusted for birth weight and exposure to furry pets and mold/dampness at the time of health outcome assessment (not shown). There was no good indication of non-linearity between NDVI exposures and the health outcomes when associations were examined using generalized additive models, suggesting that at least for these outcomes, a threshold value for NDVI was not apparent.

Given the substantial/considerable heterogeneity between the cohort-specific associations $\left(\mathrm{I}^{2}>0.7\right.$ for seven of the eight adjusted associations), all meta-analytic results were non-significant (Supplemental Information, Table S2).

296 Although at least one interaction term between NDVI in a 500m buffer and each potential effect 297 modifier considered was significant for at least one cohort, results were not consistent across cohorts 298 and all interaction terms in the combined analyses were non-significant (Supplemental Information, 299 Table S3). In line with this, associations stratified by sex (Supplemental Information, Figure S3) as well 300 as $\mathrm{NO}_{2}$ (Supplemental Information, Figure S4) and population density (Supplemental Information, 301 Figure S5) tertiles did not reveal consistent patterns within or between cohorts. Stratification by 302 whether participants' lived in urban or rural surroundings yielded weak evidence for stronger positive 
303 effects in urban settings in the cohorts for which greenness was positively associated with the health 304 outcomes (BAMSE and GINI/LISA South; Supplemental Information, Figure S6), but confidence 305 intervals overlapped. Independently adjusting the main models for $\mathrm{NO}_{2}$, population density and urban 306 versus rural categorical variables did not change the results, although the effect estimates for BAMSE 307 were attenuated after adjustment for population density and urban versus rural surroundings (for 308 example, $1.18[0.81,1.72]$ and $1.10[0.78,1.54]$, respectively, compared to $1.42[1.13,1.79]$, for the 309 association between childhood allergic rhinitis and NDVI in a 500m buffer). Finally, models stratified 310 by moving behaviour did not yield consistent differences between groups (Supplemental Information, 311 Figure S7).
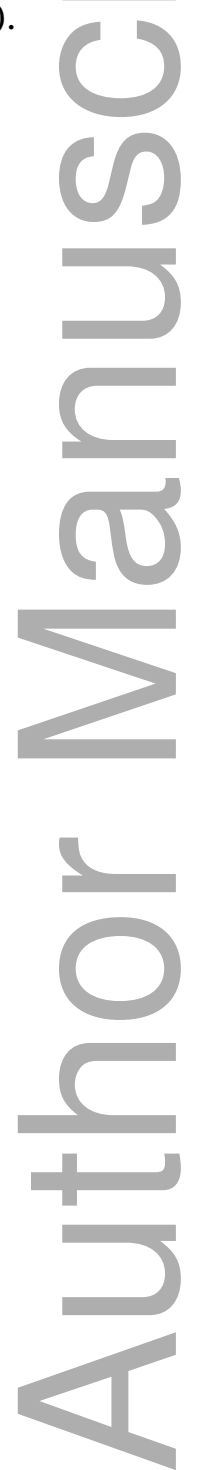

This article is protected by copyright. All rights reserved 


\section{DISCUSSION}

313 Mean NDVI in a 500m buffer was differentially associated with allergic rhinitis and aeroallergen

314 sensitization in this analysis of seven birth cohorts, resulting in an overall non-significant combined

315 finding. Evaluating sex, $\mathrm{NO}_{2}$ exposure, population density and an urban/rural marker as effect

316 modifiers did not clarify these trends. Confounding by an unknown factor that varies between-study

317 areas or by several region-specific confounders may be a possible explanation. Alternatively, our

318 results may be simply driven by chance.

320 It may be worth asking whether a combined meta-analysis is appropriate in this study, given the 321 considerable/substantial heterogeneity observed in the cohort-specific results. We chose to present the 322 meta-analytic results as they answer our original research question. However, the most important lesson from this study may not lie in the direction of the effect estimates but rather upon the use of the NDVI in allergic health research. Although the NDVI is able to capture small-scale greenness in a standardized and objective manner, it does not allow particular types of vegetation to be distinguished, nor are we able to derive individual-level measures of exposure to pollen or other allergenic tree species. The duration and character of potential exposures can also not be assessed. For example, the extent to which NDVI serves as a proxy for exposure to pollen or microbial diversity, or an indicator of areas conductive to physical activity or social interactions, or a proxy for visual impacts related to stress reduction is unclear. We are thus not able to identify which, if any, particular vegetation types, exposure pathway(s) or duration of exposures may drive the observed associations. Consequently, although the use of the NDVI to assess vegetation may be well justified for the evaluation of potential pathways related to stress and for certain health outcomes (for example, birth weight, physical activity and mental health), it appears to be too general of a measure to completely capture the full structure and potential role of the green environment with respect to allergic diseases. We thus caution against its further use in the allergic field and rather recommend that future studies use more detailed data on local tree and herbaceous species and on interactions between people and various measures of vegetation when exploring the role of the residential green environment and the overall living environment on allergic health outcomes. Such measures naturally are more focused on pathways related to pollen dispersion and microbial diversity.

342 The current study nevertheless has several strengths. It is the largest analysis of residential greenness 
on childhood allergic health outcomes to date and the first to include individual-level data from more

344 than one continent. The majority of the health and covariate data had been previously harmonized for 345 these cohorts $(21,22)$, although the allergic rhinitis definitions differed slightly as did the number of objectively measured aeroallergens tested. Also, two cohorts were high allergy-risk by design (MACS and SAGE). These factors could have affected the cohort-specific outcome prevalences, but not necessarily the associations. The high outcome prevalences for some of the cohorts may also have resulted in odd ratios that overestimate the true relative risks, although the overall conclusions of this study would not be affected (34). Several covariates were adjusted for in this analysis, but residual confounding is always possible in observational studies. For example, although models were adjusted for a marker of individual-level socioeconomic status and consistent evidence of effect modification by this factor was not detected (not shown), our measures of individual-level socioeconomic status may not be optimal. It is also possible that area-level factors may play a role.

Data were prospectively collected for all cohorts except SAGE. Thus, we anticipate that recall bias should be minimal, but remains possible, as does selection bias due to loss of follow-up. Given the cross-sectional design of the analyses, bias related to moving or the effect of timing of exposures (current versus early) was not directly assessed. Findings from a previous study indicate that the green environment around the home at birth may be more strongly associated with allergies later in life than the current home green environment for children that have moved (8). In our study, models stratified by whether a child had moved between birth and the time of outcome assessment did not yield consistent trends. Further, it is unlikely that any bias related to the length of residence at the current address would differentially affect the results across cohorts.

The harmonized greenness assignment across studies is also an important strength of this study, but is not without limitations. First, it was not possible to obtain cloud-free images for the same months and years for all cohorts. NDVI estimates were derived from images as close in time as possible during spring and summer months to achieve maximum exposure contrasts between areas of low and high greenness. Second, we related NDVI values derived from maps taken at the time of birth to health outcomes 6-12 years later assuming that the spatial variability in greenness exposures would not have changed during this time, an approach often used in air pollution research (22). This assumption is supported by the fact that a second set of NDVI values derived from satellite images taken ten years

This article is protected by copyright. All rights reserved 
374 after the birth of the participants were highly correlated with the main NDVI estimates and yielded no

375 differences in the results. This finding suggests that the spatial distribution of residential greenness was 376 temporally stable during the time frame covered in this study (early/mid 1990s to middle/late 2000s) in 377 the areas investigated. Further studies are needed to confirm whether this finding is also valid in other 378 parts of the world, particularly in developing countries where land use patterns might change more 379 rapidly. Third, our decision to assess associations with greenness in 500m and 1000m buffers around 380 the home address did not allow the study of the effect of greenness on a very small (in a 100m buffer) 381 or large scale (for example, $3000 \mathrm{~m}$ buffer or even at the city-level). The $500 \mathrm{~m}$ buffer around the home 382 address was a priori selected as the main buffer of interest as it is a proximal measure of a child's 383 neighbourhood and is likely to incorporate less exposure misclassification than larger buffers, although 384 it is well-known that pollen can travel much larger distances (35). The optimal buffer size to use when 385 studying similar associations remains to be determined. Fourth, we chose to limit our analysis to 386 vegetation levels around the home address and did not assess associations with types of green space or 387 land use classifications (e.g. presence or percentage of parks, forest and agriculture) as standard data of 388 this type (e.g. the CORINE data) were only available for the European cohorts and, like the NDVI, do 389 not provide information on vegetation types.

Although the evidence supporting a beneficial effect of greenness on several health measures is increasing, studies on allergic health outcomes remain inconsistent. In this harmonized analysis of seven birth cohorts from three continents, the direction of the association between mean NDVI in a $500 \mathrm{~m}$ buffer and allergic rhinitis and aeroallergen sensitization varied by region, resulting in a nonsignificant combined finding. Our results thus suggest that using the NDVI as a marker for residential greenness may only have local interpretations. Alternatively, it is possible that there is no real association between residential greenness and allergic health, and that the observed effects are driven by chance or unknown confounding (region-specific) factors.

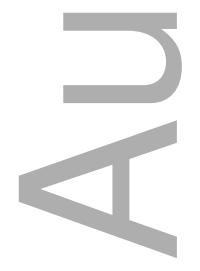

This article is protected by copyright. All rights reserved 
400 We thank all children and parents for their cooperation, and all technical and administrative support 401 staff and medical and field work teams. We also thank all BAMSE, CAPPS, GINIplus, LISAplus, 402 MACS, PIAMA and SAGE investigators.

403

\section{CONFLICT OF INTEREST STATEMENT}

405 All co-authors have no conflicts of interest.

406

407

408

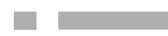

\section{AUTHOR CONTRIBUTIONS}

409

EF, IM and JH designed the study. EF wrote the initial draft and had final responsibility for the decision 410 to submit for publication. EF, GB and OG conducted the statistical analyses. IM, GB, MK, UG, DS, $\mathrm{MB}$ and $\mathrm{CC}$ contributed to the greenness exposure assignment. ABecker, DB, AvB, ABergström, BB, IB, MC-Y, SCD, UG, BH, CK, GHK, AK, IK, CL, AL, EM, GP, MS and AW contributed to the collection and/or provided the health and covariate data. All authors provided substantial contributions to the conception or design of the work, or the acquisition, analysis, or interpretation of data for the work, revised the manuscript for important intellectual content, approved the final version and agreed to be accountable for all aspects of the work.

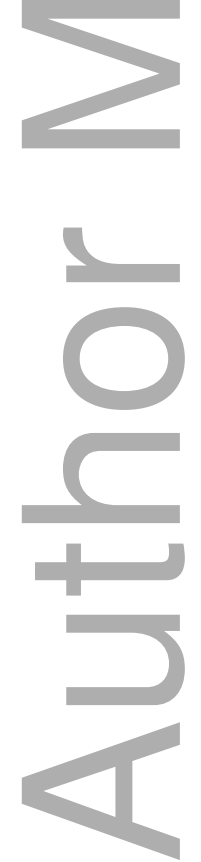

This article is protected by copyright. All rights reserved 
1. Hartig T, Mitchell R, de Vries S, Frumkin H. Nature and Health. Annu Rev Public Health. 2014;35(1):21.1-21.22. DOI:10.1146/annurev-publhealth-032013-182443

2. Hanski I, Hertzen L von, Fyhrquist N, Koskinen K, Torppa K, Laatikainen T, et al. Environmental biodiversity, human microbiota, and allergy are interrelated. Proc Natl Acad Sci.

2012;109(21):8334-9. DOI:10.1073/pnas.1205624109

3. Von Hertzen L, Hanski I, Haahtela T. Natural immunity: biodiversity loss and inflammatory diseases are two global megatrends that might be related. EMBO Rep. 2011;12(11):1089-93. DOI:10.1038/embor.2011.195

4. Lynch SV, Wood RA, Boushey H, Bacharier LB, Bloomberg GR, Kattan M, et al. Effects of earlylife exposure to allergens and bacteria on recurrent wheeze and atopy in urban children. J Allergy Clin Immunol. 2014 Sep 1;134(3):593-601.e12.

5. Cakmak S, Dales RE, Burnett RT, Judek S, Coates F, Brook J. Effect of airborne allergesn on emergency visits by children for conjunctivities and rhinitis. Lancet. 2002;359(9310):947-948. DOI:10.1016/S0140-6736(02)08045-5

6. Lovasi GS, O'Neil-Dunne JPM, Lu JWT, Sheehan D, Perzanowski MS, MacFaden SW, et al. Urban tree canopy and asthma, wheeze, rhinitis, and allergic sensitization to tree pollen in a New York City birth cohort. Environ Health Perspect. 2013;121(4):494-500.

DOI:10.1289/ehp.1205513

7. Fuertes E, Butland BK, Ross Anderson H, Carlsten C, Strachan DP, Brauer M. Childhood intermittent and persistent rhinitis prevalence and climate and vegetation: a global ecologic analysis. Ann Allergy Asthma Immunol. 2014;113(4):386-92.e9. DOI:10.1016/j.jaci.2013.03.007

8. Ruokolainen L, von Hertzen L, Fyhrquist N, Laatikainen T, Lehtomäki J, Auvinen P, et al. Green areas around homes reduce atopic sensitization in children. Allergy. 2015;70(2):195-202. DOI:10.1111/all.12545

9. Fuertes E, Markevych I, Berg A von, Bauer C-P, Berdel D, Koletzko S, et al. Greenness and allergies: evidence of differential associations in two areas in Germany. J Epidemiol Community

This article is protected by copyright. All rights reserved 
Health. 2014;68(8):787-790. 8. DOI:10.1136/jech-2014-203903

10. Dadvand P, Villanueva CM, Font-Ribera L, Martinez D, Basagaña X, Belmonte J, et al. Risks and benefits of green spaces for children: a cross-sectional study of associations with sedentary behavior, obesity, asthma, and allergy. Environ Health Perspect. 2014;122(12):1329-35. DOI:10.1289/ehp.1308038.

11. Richardson EA, Mitchell R, Hartig T, Vries S de, Astell-Burt T, Frumkin H. Green cities and health: a question of scale? J Epidemiol Community Health. 2012;66(2):160-5.

DOI:10.1136/jech.2011.137240

12. Maas J, Verheij RA, Vries S de, Spreeuwenberg P, Schellevis FG, Groenewegen PP. Morbidity is related to a green living environment. J Epidemiol Community Health. 2009;63(12):967-73. DOI:10.1136/jech.2008.079038

13. Wickman M, Pershagen G, Nordvall SL. The BAMSE Project: presentation of a prospective longitudinal birth cohort study. Pediatr Allergy Immunol. 2002;13(Suppl. 15):11-3.

DOI:10.1034/j.1399-3038.13.s.15.10.x

14. Chan-Yeung M, Manfreda J, Dimich-Ward H, Ferguson A, Watson W, Becker A. A randomized controlled study on the effectiveness of a multifaceted intervention program in the primary prevention of asthma in high-risk infants. Arch Pediatr Adolesc Med. 2000;154(7):657-63. DOI:10.1001/archpedi.154.7.657

15. von Berg A, Krämer U, Link E, Bollrath C, Heinrich J, Brockow I, et al. Impact of early feeding on childhood eczema: development after nutritional intervention compared with the natural course - the GINIplus study up to the age of 6 years. Clin Exp Allergy. 2010;40(4):627-36. DOI:10.1111/j.1365-2222.2009.03444.x

16. Heinrich J, Bolte G, Hölscher B, Douwes J, Lehmann I, Fahlbusch B, et al. Allergens and endotoxin on mothers' mattresses and total immunoglobulin E in cord blood of neonates. Eur Respir J. 2002;20(3):617-23. DOI:10.1183/09031936.02.02322001

This article is protected by copyright. All rights reserved 
17. Zutavern A, Brockow I, Schaaf B, Bolte G, von Berg A, Diez U, et al. Timing of solid food introduction in relation to atopic dermatitis and atopic sensitization: results from a prospective birth cohort study. Pediatrics. 2006;117(2):401-11. DOI:10.1542/peds.2004-2521

18. Lowe AJ, Carlin JB, Bennett CM, Abramson MJ, Hosking CS, Hill DJ, et al. Atopic disease and breast-feeding — cause or consequence? J Allergy Clin Immunol. 2006;117(3):682-7.

DOI:10.1016/j.jaci.2005.10.027

19. Brunekreef B, Smit J, de Jongste J, Neijens H, Gerritsen J, Postma D, et al. The prevention and incidence of asthma and mite allergy (PIAMA) birth cohort study: design and first results. Pediatr Allergy Immunol. 2002;13(15):55-60. DOI:10.1034/j.1399-3038.13.s.15.1.x

20. Kozyrskyj AL, HayGlass KT, Sandford A, Pare PD, Chan-Yeung M, Becker AB. A novel study design to investigate the early-life origins of asthma in children (SAGE study). Allergy. 2009;64(8):1185-93. DOI:10.1111/j.1398-9995.2009.02033.x

21. MacIntyre EA, Carlsten C, MacNutt M, Fuertes E, Melén E, Tiesler CMT, et al. Traffic, asthma and genetics: combining international birth cohort data to examine genetics as a mediator of traffic-related air pollution's impact on childhood asthma. Eur J Epidemiol. 2013;28(7):597-606. DOI:10.1007/s10654-013-9828-5

22. Gruzieva O, Gehring U, Aalberse R, Agius R, Beelen R, Behrendt H, et al. Meta-analysis of air pollution exposure association with allergic sensitization in European birth cohorts. J Allergy Clin Immunol. 2014;133(3):767-76.e7. DOI:10.1016/j.jaci.2013.07.048

23. Weier J, Herring D. Measuring vegetation (NDVI \& EVI) [Internet]. 2000 [cited 2013 Dec 30 ]. Available from: http://earthobservatory.nasa.gov/Features/MeasuringVegetation/printall.php

24. Markevych I, Fuertes E, Tiesler CMT, Birk M, Bauer C-P, Koletzko S, et al. Surrounding greenness and birth weight: Results from the GINIplus and LISAplus birth cohorts in Munich. Health Place. 2014;26:39-46. DOI:10.1016/j.healthplace.2013.12.001

25. Markevych I, Thiering E, Fuertes E, Sugiri D, Berdel D, Koletzko S, et al. A cross-sectional analysis of the effects of residential greenness on blood pressure in 10-year old children: results from the GINIplus and LISAplus studies. BMC Public Health. 2014;14(1):477.

This article is protected by copyright. All rights reserved 
DOI:10.1186/1471-2458-14-477

26. McMorris O, Villeneuve PJ, Su J, Jerrett M. Urban greenness and physical activity in a national survey of Canadians. Environ Res. 2015;137:94-100. DOI:10.1016/j.envres.2014.11.010

27. DerSimonian R, Laird N. Meta-analysis in clinical trials. Control Clin Trials.1986;7(3):177-88. DOI:10.1016/0197-2456(86)90046-2

28. Huedo-Medina TB, Sánchez-Meca J, Marín-Martínez F, Botella J. Assessing heterogeneity in meta-analysis: Q statistic or $\mathrm{I}^{2}$ index? Psychol Methods. 2006;11(2):193-206. DOI:10.1037/1082989X.11.2.193

29. Higgins JP, Green S. Cochrane Handbook for Systematic Reviews of Interventions. Chapter 9.5.2: Identifying and measuring heterogeneity. Version 5.1.0 [updated 2011]. Available from: http://handbook.cochrane.org/chapter_9/9_5_2_identifying_and_measuring_heterogeneity.htm.

30. Schwarzer G. meta: Meta-Analysis with R. R package version 3.7-0.http://CRAN.Rproject.org $/$ package $=$ meta

31. R Core Team. R: A language and environment for statistical computing. $\mathrm{R}$ Foundation for Statistical Computing, Vienna, Austria. ISBN 3-900051-07-0, www.R-project.org/. 2012.

32. StataCorp. Stata Statistical Software: Release 13. College Station, TX: StataCorp LP. 2013.

33. Fuertes E, Brauer M, MacIntyre E, Bauer M, Bellander T, von Berg A, et al. Childhood allergic rhinitis, traffic-related air pollution, and variability in the GSTP1, TNF, TLR2, and TLR4 genes: Results from the TAG Study. J Allergy Clin Immunol. 2013;132(2):342-52.e2. DOI:10.1016/j.jaci.2013.03.007

34. Davies HTO, Crombie IK, Tavakoli M. When can odds ratios mislead. BMJ. 1998;316(7136):989991. DOI:10.1136/bmj.316.7136.989

35. D’Amato G, Cecchi L, Bonini S, Nunes C, Annesi-Maesano I, Behrendt H, et al. Allergenic pollen and pollen allergy in Europe. Allergy. 2007;62(9):976-90. DOI:10.1111/j.13989995.2007.01393.x 
Table 1: Summary statistics of the study population

\begin{tabular}{|c|c|c|c|c|c|c|c|c|c|c|c|c|c|c|}
\hline \multirow{2}{*}{ ( } & \multicolumn{2}{|c|}{$\begin{array}{c}\text { BAMSE } \\
\mathrm{N}_{\text {total }}=3304\end{array}$} & \multicolumn{2}{|c|}{$\begin{array}{c}\text { CAPPS } \\
\mathrm{N}_{\text {total }}=357\end{array}$} & \multicolumn{2}{|c|}{$\begin{array}{l}\text { GINI/LISA } \\
\text { North } \\
\mathrm{N}_{\text {total }}=2152\end{array}$} & \multicolumn{2}{|c|}{$\begin{array}{l}\text { GINI/LISA } \\
\text { South } \\
\mathrm{N}_{\text {total }}=2855\end{array}$} & \multicolumn{2}{|c|}{$\begin{array}{c}\text { MACS } \\
\mathrm{N}_{\text {total }}=327\end{array}$} & \multicolumn{2}{|c|}{$\begin{array}{c}\text { PIAMA } \\
\mathrm{N}_{\text {total }}=3339\end{array}$} & \multicolumn{2}{|c|}{$\begin{array}{c}\text { SAGE } \\
\mathrm{N}_{\text {total }}=682\end{array}$} \\
\hline & $\mathrm{n}$ & $\%$ & $\mathrm{n}$ & $\%$ & $\mathrm{n}$ & $\%$ & $\mathrm{n}$ & $\%$ & $\mathrm{n}$ & $\%$ & $\mathrm{n}$ & $\%$ & $\mathrm{n}$ & $\%$ \\
\hline \multicolumn{15}{|l|}{$\begin{array}{l}\text { Outcomes } \\
\text { Childhood (6-8 yrs) }\end{array}$} \\
\hline Allergic rhiniti & 422 & 13.4 & 105 & 29.4 & 96 & 4.8 & 174 & 6.3 & - & - & 211 & 6.6 & 174 & 33.2 \\
\hline Aeroallergen sensitization & 623 & 28.5 & 154 & 44.8 & 256 & 26.1 & 481 & 31.1 & - & - & 543 & 32.5 & 189 & 27.9 \\
\hline Indoor aeroallergen sensitization & 413 & 20.9 & 126 & 36.6 & 174 & 17.8 & 276 & 17.9 & - & - & 432 & 25.8 & 127 & 18.7 \\
\hline $\begin{array}{l}\text { Outdoor aeroallergen sensitization } \\
\text { Early adolescence (10-12 yrs) }\end{array}$ & \multicolumn{14}{|c|}{ Early adolescence (10-12 yrs) } \\
\hline Allergic rhinitis & 587 & 19.2 & - & - & 132 & 8.0 & 249 & 10.9 & 118 & 37.0 & 260 & 10.1 & - & - \\
\hline Aeroallergen sensitization & - & - & - & - & 300 & 34.8 & 626 & 43.0 & 180 & 55.1 & 544 & 42.6 & - & - \\
\hline Indoor aeroallergen sensitization & - & - & - & - & 211 & 24.5 & 407 & 28.0 & 166 & 50.8 & 437 & 34.2 & - & - \\
\hline \multicolumn{15}{|l|}{ Covariates } \\
\hline Age at childhood ${ }^{1}$ & 8.2 & $(0.5)$ & 7.2 & $(0.2)$ & 6.1 & $(0.3)$ & 6.0 & $(0.1)$ & - & - & 8.1 & $(0.2)$ & 9.1 & $(0.5)$ \\
\hline Age at early adolescence ${ }^{1}$ & 13.0 & $(0.8)$ & - & - & 10.1 & $(0.2)$ & 10.1 & $(0.2)$ & 11.2 & $(2.1)$ & 11.4 & $(0.3)$ & - & - \\
\hline Male sex & 1668 & 50.5 & 194 & 54.3 & 1094 & 50.8 & 1469 & 51.5 & 172 & 52.6 & 1720 & 51.5 & 379 & 55.6 \\
\hline Birth weight (grams) ${ }^{1}$ & 3528.7 & $(557.3)$ & 3482.1 & $(650.6)$ & 3536.8 & $(478.4)$ & 3415.1 & $(433.7)$ & - & - & 3521.3 & $(540)$ & 3378.9 & $(636.7)$ \\
\hline Parental atopy & 1007 & 30.8 & 331 & 92.7 & 1005 & 47.0 & 1875 & 66.1 & 309 & 94.8 & 1666 & 49.9 & 395 & 58.7 \\
\hline Older siblings & 1602 & 48.5 & 198 & 55.5 & 1174 & 54.8 & 1231 & 43.2 & 204 & 62.4 & 1680 & 50.3 & 433 & 73.3 \\
\hline
\end{tabular}

This article is protected by copyright. All rights reserved 


\begin{tabular}{|c|c|c|c|c|c|c|c|c|c|c|c|c|c|c|c|}
\hline \multicolumn{2}{|c|}{ Maternal smoking during pregnancy } & 415 & 12.6 & 29 & 8.2 & 321 & 15.1 & 375 & 13.4 & 13 & 4.00 & 537 & 16.2 & 131 & 20.0 \\
\hline \multirow[t]{3}{*}{ Parental education $^{2}$} & Low & 64 & 2.0 & - & - & 272 & 12.7 & 144 & 5.1 & 83 & 25.4 & 400 & 12.0 & - & - \\
\hline & Med & 1410 & 43.9 & - & - & 875 & 40.8 & 513 & 18.0 & - & - & 1210 & 36.4 & - & - \\
\hline & High & 1740 & 54.1 & - & - & 999 & 46.6 & 2188 & 76.9 & 244 & 74.6 & 1716 & 51.6 & - & - \\
\hline \multicolumn{2}{|c|}{ Maternal age (years) ${ }^{1}$} & 30.8 & $(4.5)$ & 31.9 & $(5.0)$ & 30.8 & $(3.8)$ & 32.4 & $(4.1)$ & 32.2 & $(4.1)$ & 30.5 & $(3.8)$ & 28.9 & $(5.3)$ \\
\hline \multirow[t]{2}{*}{ Intervention } & Active & - & - & 167 & 46.8 & 727 & 33.8 & 852 & 29.8 & 109 & 33.3 & 309 & 9.3 & - & - \\
\hline & Placebo & - & - & - & - & - & - & - & - & - & - & 272 & 8.1 & - & - \\
\hline \multicolumn{16}{|l|}{ Childhood (6-8 yrs) } \\
\hline \multicolumn{2}{|c|}{ Tobacco smoke at home } & 579 & 18.6 & 67 & 18.8 & 795 & 38.4 & 545 & 19.8 & - & - & 494 & 15.6 & 182 & 27.5 \\
\hline \multicolumn{2}{|c|}{ Furry pets at home } & 828 & 26.2 & 34 & 9.5 & 583 & 28.1 & 673 & 24.0 & - & - & 1697 & 54.5 & 424 & 62.9 \\
\hline \multicolumn{2}{|c|}{ Mold/dampness at home } & 250 & 7.9 & 175 & 49.0 & 306 & 15.0 & 590 & 21.9 & - & - & 913 & 29.0 & 475 & 69.9 \\
\hline \multicolumn{2}{|c|}{$\mathrm{NO}_{2}$ concentration $^{1}\left(\mu \mathrm{g} / \mathrm{m}^{3}\right)$} & 11.9 & $(5.0)$ & 19.5 & $(11.3)$ & 23.5 & $(3.1)$ & 20.1 & $(5.3)$ & - & - & 22.0 & $(6.1)$ & 8.1 & $(2.1)$ \\
\hline \multicolumn{2}{|c|}{ Population density ${ }^{3}$ (1000m buffer) } & 9341 & $(15602)$ & - & - & 1218 & (1678) & 2829 & (3389) & - & - & 7359 & $(8395)$ & - & - \\
\hline \multicolumn{2}{|c|}{ Living in an urban surrounding ${ }^{4}$} & 1117 & 33.8 & - & - & 24 & 1.1 & 1452 & 51.1 & - & - & 661 & 20.9 & - & - \\
\hline \multicolumn{2}{|l|}{ Moved since birth } & 2161 & 66.7 & - & - & 713 & 34.1 & 1378 & 48.5 & - & - & 1611 & 50.8 & - & - \\
\hline \multicolumn{16}{|c|}{ Early adolescence (10-12 yrs) } \\
\hline \multicolumn{2}{|c|}{ Tobacco smoke at home } & 435 & 16.1 & - & - & 464 & 27.8 & 309 & 13.2 & - & - & 299 & 11.6 & - & - \\
\hline \multicolumn{2}{|c|}{ Furry pets at home } & 709 & 22.9 & - & - & 596 & 36.0 & 822 & 35.5 & - & - & 1541 & 59.8 & - & - \\
\hline \multicolumn{2}{|c|}{ Mold/dampness at home } & 261 & 9.9 & - & - & 317 & 19.6 & 504 & 22.3 & - & - & 841 & 32.6 & - & - \\
\hline \multicolumn{2}{|c|}{$\mathrm{NO}_{2}$ concentration $^{1}\left(\mu \mathrm{g} / \mathrm{m}^{3}\right)$} & 11.5 & $(5.6)$ & - & - & 23.7 & $(3.4)$ & 19.8 & $(5.2)$ & $242^{5}$ & $(293)^{5}$ & 21.8 & $(6.1)$ & - & - \\
\hline \multicolumn{2}{|c|}{ Population density ${ }^{3}$ (1000m buffer) } & 8315 & $(12778)$ & - & - & 1309 & $(1852)$ & 2673 & $(3258)$ & 5131 & $(5488)$ & 7076 & $(8677)$ & - & - \\
\hline \multicolumn{2}{|c|}{ Living in an urban surrounding ${ }^{4}$} & 893 & 27.0 & - & - & 26 & 1.2 & 1333 & 48.8 & - & - & 515 & 19.9 & - & - \\
\hline \multicolumn{2}{|l|}{ Moved since birth } & 2680 & 82.3 & - & - & 811 & 47.2 & 1546 & 64.1 & 173 & 53.0 & 1559 & 60.2 & - & - \\
\hline
\end{tabular}

This article is protected by copyright. All rights reserved 
$421{ }^{1}$ Mean (standard deviation)

$422{ }^{2}$ Defined as the highest education attained by either parent

$423{ }^{3}$ Medium (interquartile range) reported

$424{ }^{4}$ Defined as $>=25 \%$ of sealed soil in a 5000m buffer around the home address for BAMSE, GINI/LISA North, GINI/LISA South and PIAMA. Data only available for 425 the European cohorts.

$426{ }^{5}$ Minimum distance to a major road in meters (medium (interquartile range)) reported instead as NO2 concentration data were not available for MACS

427 - : not available/not applicable

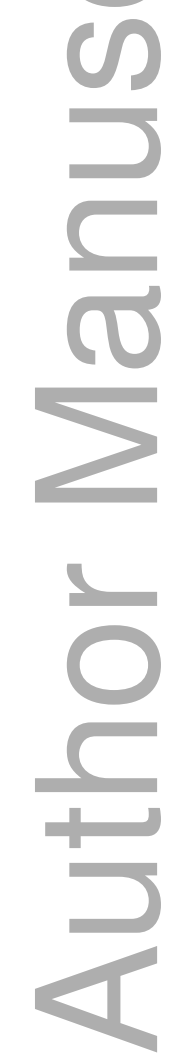

This article is protected by copyright. All rights reserved 
428 FIGURE LEGENDS:

429 Figure 1: Cohort-specific distribution of mean NDVI in a 500m buffer around the home addresses in 430 childhood (6-8 years) and early adolescence (10-12 years). Comparisons across cohorts are not 431 appropriate as it was not possible to obtain cloud-free images at the same time for all cohorts. na $=$ not 432 available

433 Figure 2: Adjusted associations between allergic rhinitis and overall, indoor and outdoor aeroallergen 434 sensitization assessed during childhood (6-8 years) with mean NDVI in a 500m buffer.

435 Figure 3: Adjusted associations between allergic rhinitis and overall, indoor and outdoor aeroallergen 436 aeroallergen sensitization assessed during early adolescence (10-12 years) with mean NDVI in a 500m 437 buffer.

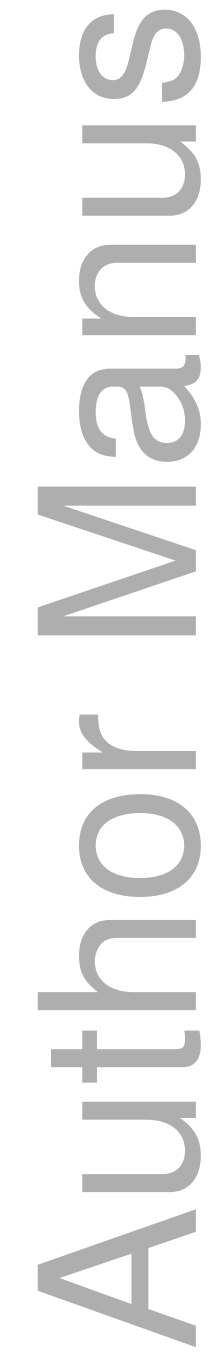

This article is protected by copyright. All rights reserved 

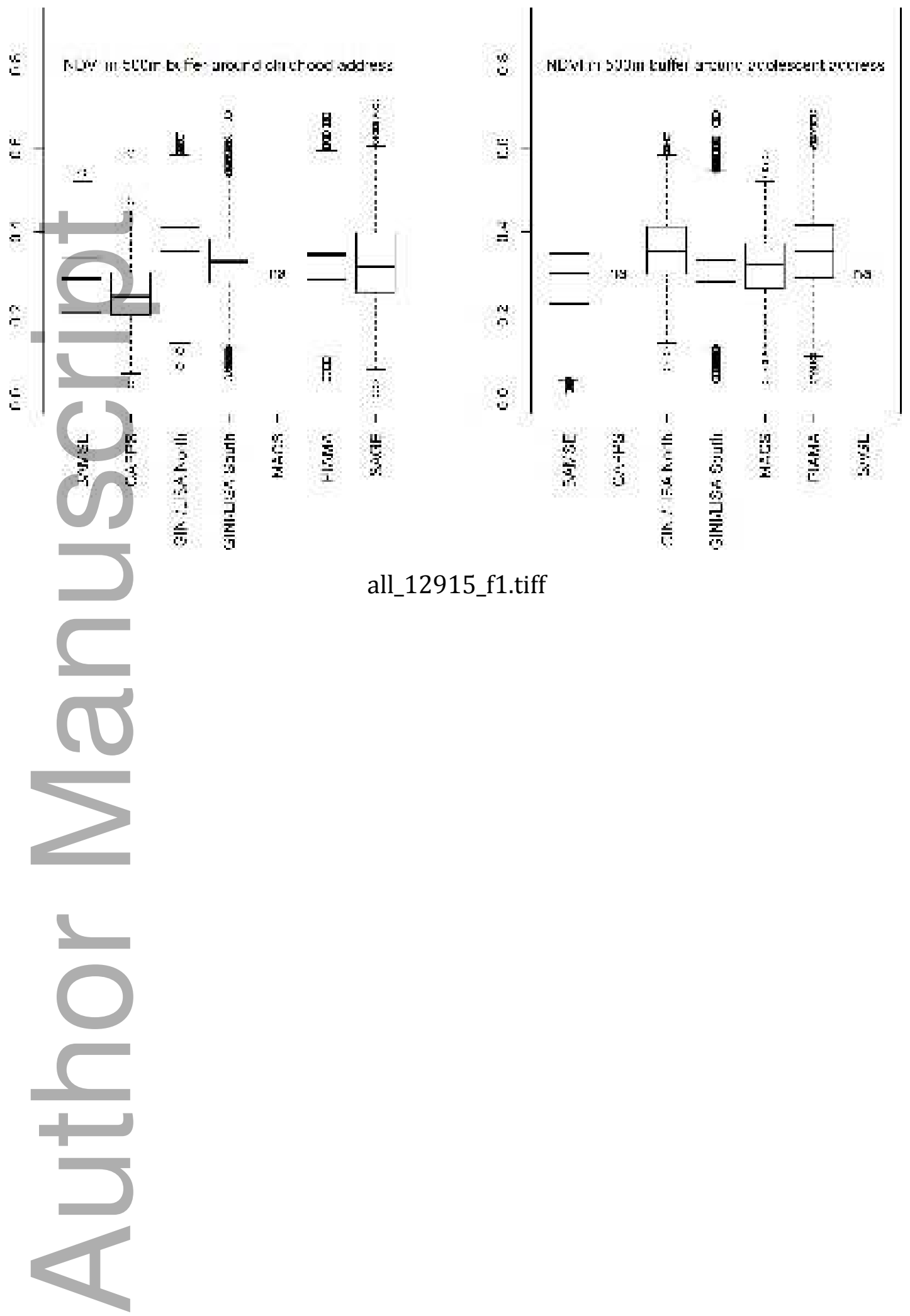


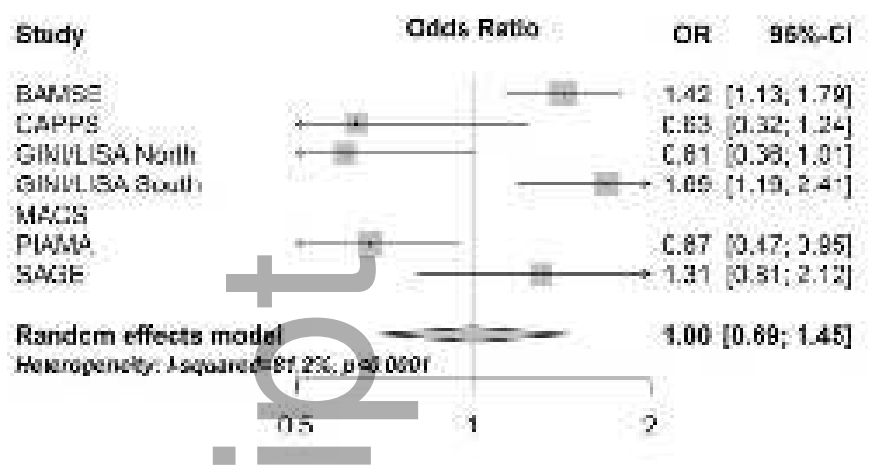

Study

BANASE

CAITS

GIN ILISA North

GiN.Lise Siveth

HACS

PAHA

SAGE

Randam effects model

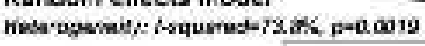

Oeds Rato OR $\quad 95 \%-\mathrm{Cl}$

Indoce earosllergen senshizatlon at G-D yoars

05

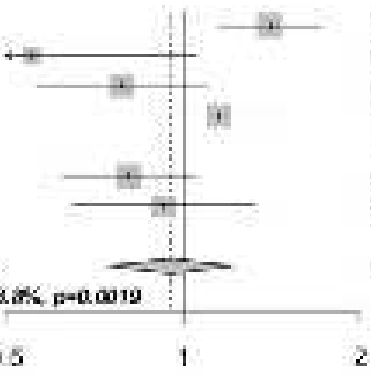

2. 1.15:1.79

$0.56 \quad 0.29,1.06$

0. $790.53 ; 1.10$

1.15 $0.35 ; 1.40$.

แ1. 부 $0.42 ; 105$

$0.93 \quad 0.75,732]$

$0.96[0.76 ; 1.22]$

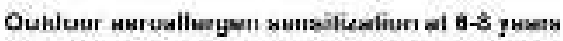
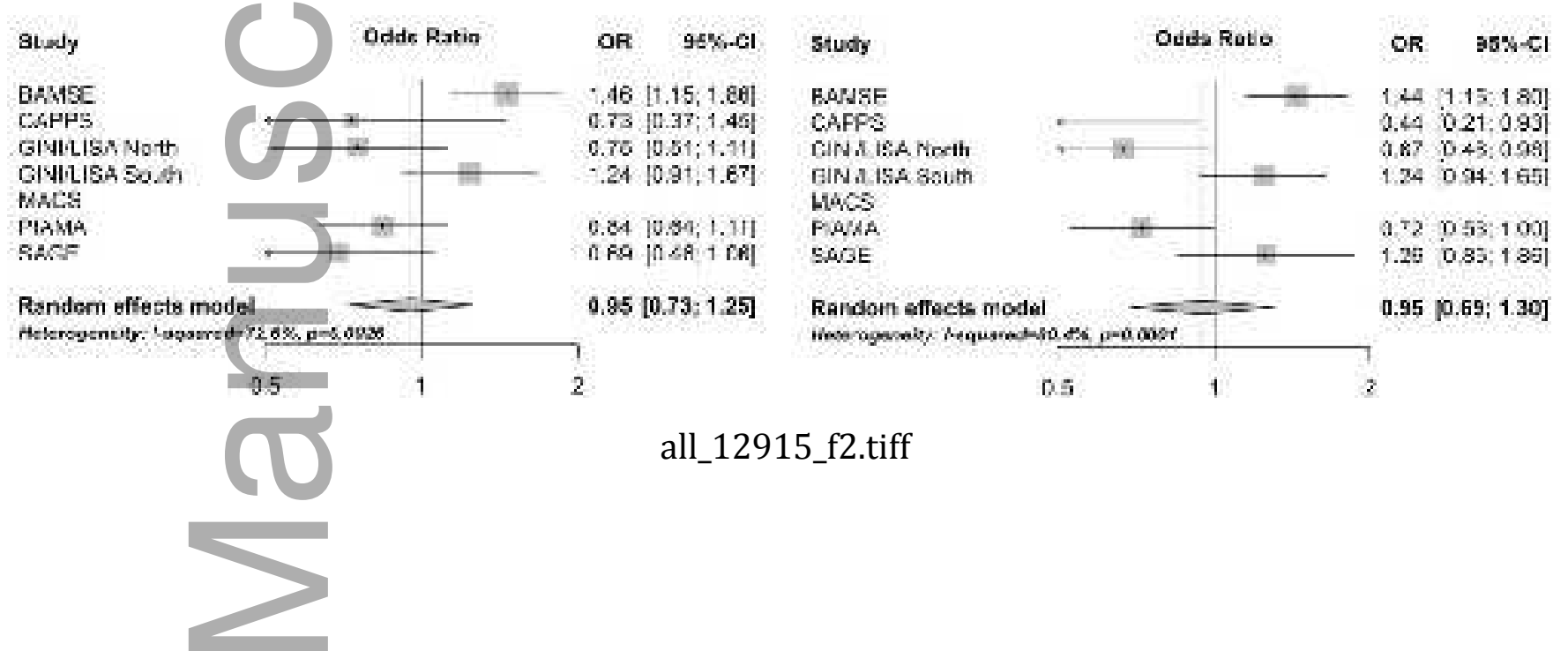

$7,46[1.15 ; 1.86] \quad$ BAOJSEF

CIN S ISA Nreth

GINA. ISA Bouth

SABE

Random effects model

12915 f2.tiff

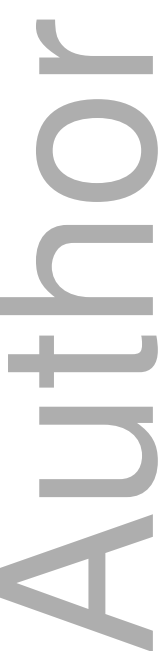

This article is protected by copyright. All rights reserved 


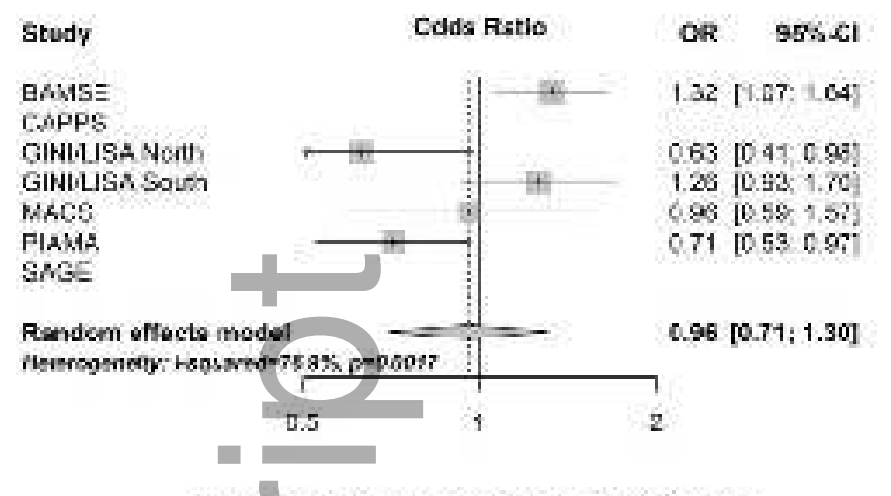

Study

Odds Ratio

OR $\quad 95 \%-\mathrm{C}$

BABASE

rants

GIRLLEA Nart

Glkbusa soun

Mace

FIASAA

SACE

Indoor aeroallergen sensitization at 10-12 years

Randiom cifects mods

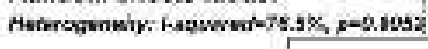

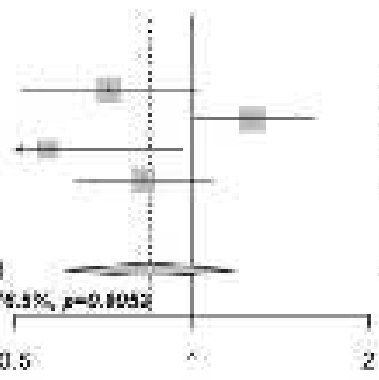

0.72 แ4.E1: 1.12

$127, \mathrm{CD}, 1.60$

$0 \leq 7$ in. 54, C...6

OB3 ju.CA: 1.LS

$0.85[0.54: 1.18]$
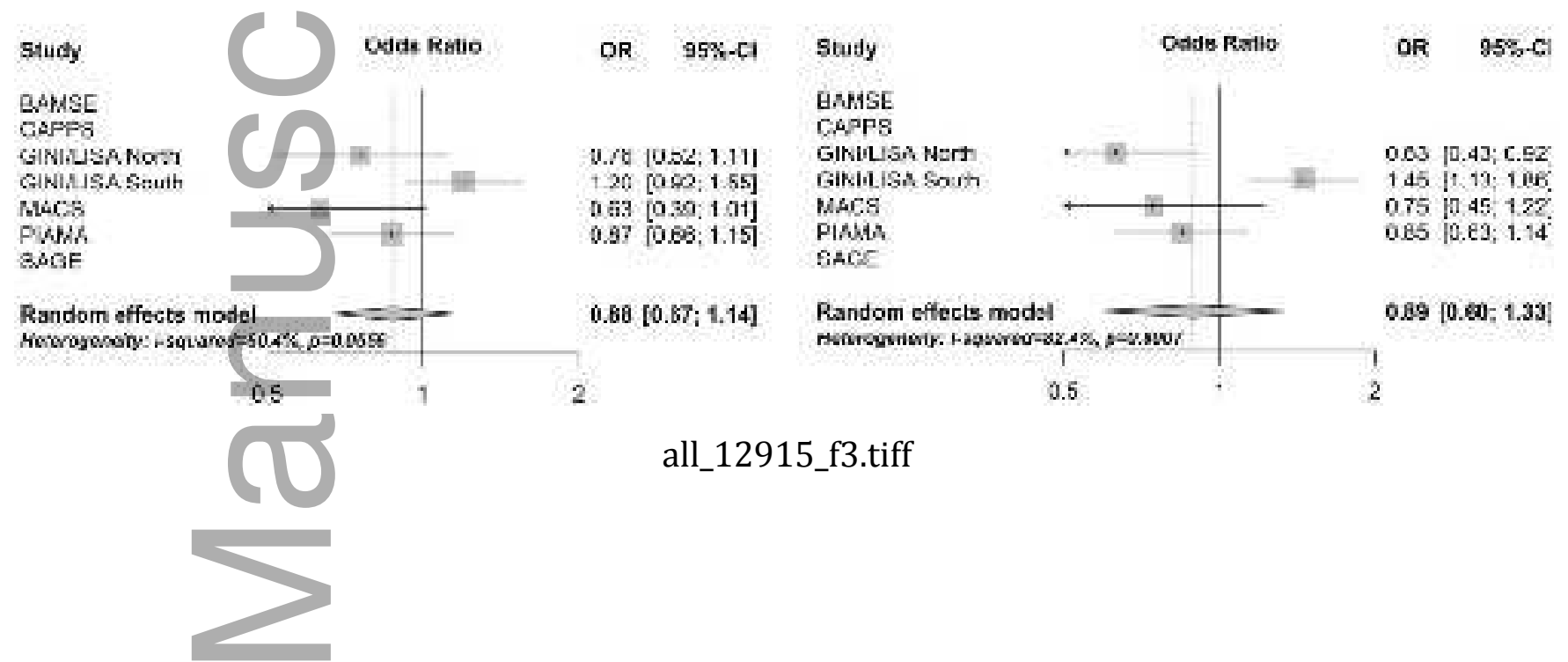

Outdoor acroallergen sensitzation at $10-12$ years

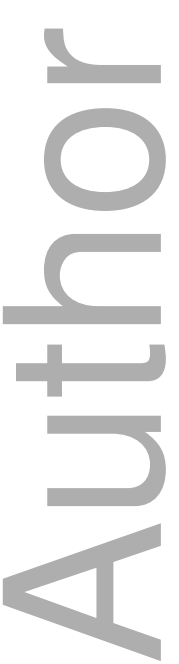

This article is protected by copyright. All rights reserved 


\section{University Library}

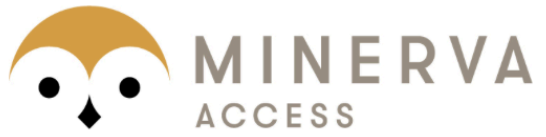

A gateway to Melbourne's research publications

Minerva Access is the Institutional Repository of The University of Melbourne

\section{Author/s:}

Fuertes, E;Markevych, I;Bowatte, G;Gruzieva, O;Gehring, U;Becker, A;Berdel, D;von Berg, A;Bergstrom, A;Brauer, M;Brunekreef, B;Brueske, I;Carlsten, C;Chan-Yeung, M;Dharmage, SC;Hoffmann, B;Kluemper, C;Koppelman, GH;Kozyrskyj, A;Korek, M;Kull, I;Lodge, C;Lowe, A;MacIntyre, E;Pershagen, G;Standl, M;Sugiri, D;Wijga, A;Heinrich, J

Title:

Residential greenness is differentially associated with childhood allergic rhinitis and aeroallergen sensitization in seven birth cohorts

Date:

2016-10-01

\section{Citation:}

Fuertes, E., Markevych, I., Bowatte, G., Gruzieva, O., Gehring, U., Becker, A., Berdel, D., von Berg, A., Bergstrom, A., Brauer, M., Brunekreef, B., Brueske, I., Carlsten, C., ChanYeung, M., Dharmage, S. C., Hoffmann, B., Kluemper, C., Koppelman, G. H., Kozyrskyj, A. ,... Heinrich, J. (2016). Residential greenness is differentially associated with childhood allergic rhinitis and aeroallergen sensitization in seven birth cohorts. ALLERGY, 71 (10), pp.1461-1471. https://doi.org/10.1111/all.12915.

Persistent Link:

http://hdl.handle.net/11343/291285 